\title{
Gamifying informal learning activities using interactive displays: an empirical investigation of students' learning and engagement
}

\author{
Ioannis Leftheriotis ${ }^{*}$, Michail N. Giannakos and Letizia Jaccheri
}

\author{
* Correspondence: iolef@acm.org \\ Department of Computer Science, \\ Norwegian University of Science \\ and Technology, Sem Sælands vei \\ 7-9, Trondheim, Norway
}

\begin{abstract}
Interactive displays (IDs) are increasingly employed in informal learning environments, where they are seen as a medium for enhancing students' creativity, and engagement. Due to the larger space they provide and thus the larger interaction area, they allow for group-work, working in parallel, co-creating artifacts or co-experiencing the interaction in a playful manner. In particular, gaming activities in IDs enhance students' mental exercise and fantasy and promote students engagement through rewards and collaboration. However, despite the increased prevalence of interactive displays and gamification, we know very little about how designers and instructors can gamify their learning activities by taking advantage of the IDs. In this paper, a framework for developing gamified activities for interactive displays is presented. For the empirical evaluation, pre-post attitudinal surveys and cognitive tests along with photos and observations were recorded and used. The contribution of this article is twofold: 1) an adaptable framework for developing gamified activities on interactive displays (GAID), and 2) the results of a field study where students have been engaged with an interactive display application during an extracurricular activity. By incorporating GAID to a traditional informal learning activity, it is found that students' knowledge acquisition, satisfaction, enjoyment and intention to participate on similar events in the future are significantly improved.
\end{abstract}

Keywords: Interactive Displays, Gamification, Informal Learning, Empirical Evaluation, Knowledge Acquisition

\section{Introduction}

With advances in interactive displays technology and increased levels of affordability in recent years, there has been a growing interest in exploring their use within educational contexts. Large interactive displays are now available through several vendors and many learning applications have emerged. Informal learning environments, like museums, science centers and aquariums, have received particular attention from the education research community, as supporting social interaction and collaboration is highly related with learning and engagement in informal environments (Giannakos et al., 2014). Several studies have established that interactive displays have the potential to engage students in meaningful collaborative learning, especially during an informal learning visit (Antle et al., 2011; Rick \& Rogers, 2008).

(c) The Author(s). 2017 Open Access This article is distributed under the terms of the Creative Commons Attribution 4.0 International License (http://creativecommons.org/licenses/by/4.0/), which permits unrestricted use, distribution, and reproduction in any medium, provided you give appropriate credit to the original author(s) and the source, provide a link to the Creative Commons license, and indicate if changes were made. 
Using the various affordances of interactive displays via gameful applications opens new avenues for enhancing students' mental exercise, fantasy, creativity, and communication; however, gamifying a "traditional" informal learning activity (e.g. museum visit) by exploiting interactive displays affordances, entails numerous design and development challenges (Cassell 2001; Giannakos et al., 2014; Klopfer et al., 2005). Notably, there is little evidence in the literature that clearly explains models allowing designers, developers and educators to create and put into practice engaging and efficient gameful activities on interactive displays.

Based on these conditions, the opportunity to improve interactive display game enhanced learning within the context of informal learning in science centers and museums emerge. Hence, it is of great importance to investigate: How to design gamified learning activities by exploiting interactive displays capabilities in an efficient and low cost and effort manner.

In this paper, the contribution is two-fold:

1) Presenting a framework for developing gamified activities on interactive displays (GAID),

2) Empirically investigating the added value in students' learning and engagement of interactive displays for museum informal learning.

\section{Related work}

There is growing interest in investigating the use of interactive displays in different domains, due to their decreasing cost and increasing commodity/availability. Interactive displays have been used for gaming and entertainment (Tse et al., 2011) and support informal learning activities (Klopfer et al., 2005). However, little evidence exists on how to create and put into practice engaging and efficient playful activities on interactive displays. Most studies are focused mainly on how to motivate and engage users while working on an interactive display (e.g. Haesler et al., 2016). However, there are limited resources regarding empirically tested frameworks or models.

Weitze et al. (2012) proposed a concept model for designing engaging and motivating games for learning: the Smiley-model. By conceptualizing the learning design (e.g. prerequisites for learning setting, learning goals, content) researchers produce a frame that includes the essential game elements (e.g. goal, action space, rules, feedback). Through the use of motivation factors (e.g. curiosity, competence and social relations), they propose that children will reach the serious, respectable, and core design value: fun in the educational game (Weitze et al., 2012). Increasing children's intrinsic motivation while learning seems to be an important factor. Despite the fact that Smiley-model was developed based on traditional theories (like participatory design, prototype development etc.), it is mainly considered as a theoretical model. Researchers claim that their model may be used as an inspiration for the design of other learning games. Other gamified systems have been focused on keeping users engaged while learning new techniques and tools (Dichev et al., 2014). Songer and Miyata (2014) propose a model for the design and mostly the evaluation of playful experiences in systems of learning that is based on behavioral psychology, anthropology and game studies. Their Playful affordances model propose having game-like experiences as ultimate design goals. They also propose that the best qualities of game design will need to utilize more than just 
game mechanics, namely elements that afford the autotelic experience of play. There have also been studies like Knaving and Björk (2013) that propose design suggestions for a good gamification experience. Although a reliable evaluation of such systems or concept models has yet to be performed, the early results are encouraging (Kim et al., 2015). For example, Mildner et al. (2015) conducted a user study to investigate which game characteristics can improve user's motivation and learning success on an interactive quiz game. However, in this study we highlight the need for a more tangible and structured framework for gamified activities for interactive displays that needs to be evaluated.

One of the first studies on multi-touch technology applied to education was "Readit", a game-based application, designed to support the development of reading skills in children aged 5-7 years old (Sluis et al., 2004). The results of the pilot experiment showed that children enjoyed playing the game and that the technology was not an obstacle to learning.

In another noticeable study, Piper and Hollan (2009) compare learning through multitouch technology to learning using a paper, a pencil and a desktop in a neuro-science class of 20 students at the University of California (Piper \& Hollan, 2009). They found that students studying on the multi-touch were able to overcome problems on their own and repeated activities more often. In addition, greater playfulness and enjoyment were noticed while students were working in the multi-touch display.

In a more recent study, Ardito et al. (2013) proposed a new educational format, inspired by the Discovery Learning Technique. Researchers integrate educational games, designed to be played on large multi-touch displays, with other types of formal and informal learning. Ardito et al., (2013) showed that their proposed educational format is effective and that games on these novel multi-touch systems engage pupils very much, stimulate their collaboration and help consolidating knowledge. According to the study of Hwang et al., (2015) larger multi-touch surfaces found to be more beneficial to students' learning due to the fact that students can more easily collaborate and practice their problem-solving skills.

There have been some quantitative studies in the literature investigating the use of interactive surfaces either in labs (Buisine et al., 2012) or in museums. Horn et al. (2012) describe visitor interaction with an interactive tabletop exhibit in a natural history museum. They analysed conversations between participants and quantified holding times of recruited and non-recruited groups around the interactive game-based exhibit. They show that visitors were engaged for prolonged periods of time. Along the same lines Hinrichs et al. (2011) investigate how visitors interact with a large interactive table exhibit using multi-touch gestures. Researchers quantify occurrences of various multitouch gestures around the interactive museum exhibit. In Horn et al. (2012), the concept of Active Prolonged Engagement is discussed. Researchers' goal is "to shift the role of the museum visitor from that of recipient of instructions and explanation to that of participant". Although they have managed to engage the visitors in focused, on-topic interaction with the exhibit for longer periods of time, they have not conducted research on the learning outcomes.

In Zaharias et al. (2013) empirical study, researchers assessed the learning performance and user experience between a group that followed the traditional learning procedure in a Museum and a group in which students interacted with a multi-touch application 
dedicated to the Museum. Although their results show non-statistically significant differences in the learning performance, the second group reported its perceived experience to be at significantly higher levels.

While previous studies have assessed engagement and learning with multi-touch technology, the great majority concentrate on qualitative analyses (Hinrichs \& Carpendale, 2011; Horn et al., 2012). Quantitative analyses of engagement and learning are less common, particularly for studies that have been conducted outside of laboratory or controlled settings (Horn et al., 2012).

Our aim, in contrast, is to add to this body of research by quantifying students' engagement and learning in a real-settings environment. In particular, this research is intended to shed light in the area of how interactive display games could be designed to engage students with the content during an informal learning activity. We present a framework for interactive display gamified learning applications, and then put this framework into practice. In particular, in order to validate our framework, we conducted a field study, collected empirical data and provide insights that enable scholars and educators to efficiently design and use interactive display games to support informal learning activities.

\section{Gamifying activities for interactive displays}

\section{Gamifying for learning}

Gamification is defined as "the use of game design elements in non-game contexts" aiming to increase engagement and motivation (Detering et al., 2011). The term Gamification is young, however there has been a lot of interest in both academia as well as commercial applications (Detering et al., 2011; Dominguez et al., 2013). Gamification has been used more and more to increase both user activity and retention in the fields of interaction design and digital marketing (Detering et al., 2011). It has been applied in many different fields, like finance, health, education, and entertainment media to mention few (Detering et al., 2011, p.9). According to the literature review of Hamari et al., (2014), gamification is becoming a more popular subject for academic inquiry and industry and thus, empirical results on the effectiveness of gamification are in great demand.

The area of education has received particular attention from both researchers and industry as a field to apply game concepts (Giannakos et al., 2014; Horn et al., 2012; Klopfer et al., 2005). Its motivational nature and its potential for increasing engagement are thought to have positive effects on students (Detering et al., 2011). Gamification offers concrete advantages that could be useful in a learning context: immediate feedback and reflection, competition, collaboration or self-study. According to Hamari et al.'s literature review (2014), the context of most studies on gamification is about education or learning; more importantly, all studies in this context consider the learning outcomes of gamification as mostly positive, for example, in terms of increased motivation and engagement in the learning tasks as well as enjoyment over them. On the other hand, there are certain risks in terms of content and assessments, as well as focusing on measurable results and losing important cognitive and affective aspects of learning (Dominguez et al., 2013). Hence, despite recent attention on gamification for learning, some researches claim that there is limited evidence that gamified applications designed for learning are successful (e.g., see Linehan et al., 2011) and others' studies 
point out the negative outcomes, which need to be paid attention to, such as the effects of increased competition, task evaluation difficulties and design features (Hamari et al., 2014).

\section{Proposed framework for interactive displays}

The proposed model intents to serve as a base for the design and the development of different applications; therefore, it is important that the instructions, as well as the implementation, are kept easy to follow as well as easy to modify. Features beyond the absolute core should be optional, as all features may not be interesting or suited for all variations of the application. Hence, it makes sense to keep different stages and features at a different module. By moving them into their own module, it is easy for an application to add or remove features as they gain or lose relevancy. Keeping features in separate modules has the added benefit of making them easy to maintain and modify. In addition, instructors are able to give more attention and thus extend some specific modules depending on what is their main learning aim.

The main idea is to provide a simple way to increase students' engagement with the exhibited artifacts (e.g., in a museum). The model does not aim to provide sophisticated approaches for reaching high demanding exhibits and/or students, but focuses on providing a "disruptive" low cost and low effort solution for a regular exhibition and artifacts, within a regular informal learning activity.

The proposed framework is grounded on three epistemological traditions in relation to learning: Behaviorism (knowledge is gained through experiences), Cognitivism (knowledge is negotiated through experience and thinking) and Constructivism (knowledge is constructed). Based on these epistemological traditions, we formulated the proposed framework with three different stages. According to Ertmer et al. (2013), powerful frameworks for instruction have been developed by designers inspired by these three perspectives. However, Ertmer et al. proposes that "successful instructional practices have features that are supported by virtually all three perspectives". In an effort to develop a framework that takes into account the variety in cognitive processing required by the task along with the level of the learners, the three instructional approaches are combined. In Table 1, the different stages of the framework along with their characteristics are depicted.

The three different stages intend on introducing students with exploring, applying and finally creating the exhibited artifacts. The first stage (called also exploration stage), or at the beginning of the activity, students can navigate in a playful explorative way through the artifacts and review all the metadata and the related information. This is a digital augmented space, where students can explore the artifacts in a similar manner

Table 1 The instructional approaches of the proposed framework stages

\begin{tabular}{lll}
\hline Framework stage & Instructional approach & Framework implementation approaches \\
\hline 1. Exploration stage & Behaviorism & $\begin{array}{l}\text { Navigate through / explore the artifacts } \\
\text { Gather more information (Internet / Local database) }\end{array}$ \\
2. Application stage & Cognitivism & $\begin{array}{l}\text { Short quiz game while interacting with the artifact } \\
\text { Play / Interact with co-player } \\
\text { Understand the properties of the artifact }\end{array}$ \\
3. Creation stage & Constructionism & Replicate / Create an abstract version of the artifact
\end{tabular}


to the traditional activity (Fig. 1). In this stage, instructors must mainly create a visual database with the artifacts and the information that they consider important for learning by the students.

The second stage (called also application stage) contains a simple, with progressive difficulty game/quiz (see Fig. 2); the simple quiz game can be played by two players either as a team ("team mode") or against each other ("versus mode"). The only design difference between the two modes is that in the versus mode each student has his/her own "control area" and the button supports both single and dual finger touch; this is an affordance in order to allow students to make the appropriate selection with only one button (Leftheriotis et al., 2015). The main idea for the second stage is that students should interact with the artifact centred in the middle, by manipulating it (zooming, rotating etc.). In this way they are able to find the needed information and select the correct option related to the artifact. Both options supported by imagery and a plain textual description; this allows us to decrease the text. As Dichev et al. (2014) propose, it is consisted of many short-term achievable goals to maintain engagement and is implemented as short quizzes or "well-designed bites" for the player (Weitze et al., 2012). In this stage, instructors have to design a number of such short quizzes that will make their students play with the artifact and learn about the subject. The game quiz applies certain game elements, like score, time constraints, competition, collaboration, to mention few, and aims on encouraging students to interact with the artifacts in a more prescriptive manner. Apart from the score, the application provides both sound and visual feedback to the users (depending on their answer) in order to be more entertaining. After making the respective selection, the system also gives to the users more information concerning the artifact with both visual material (pictures or videos) and additional information in text.

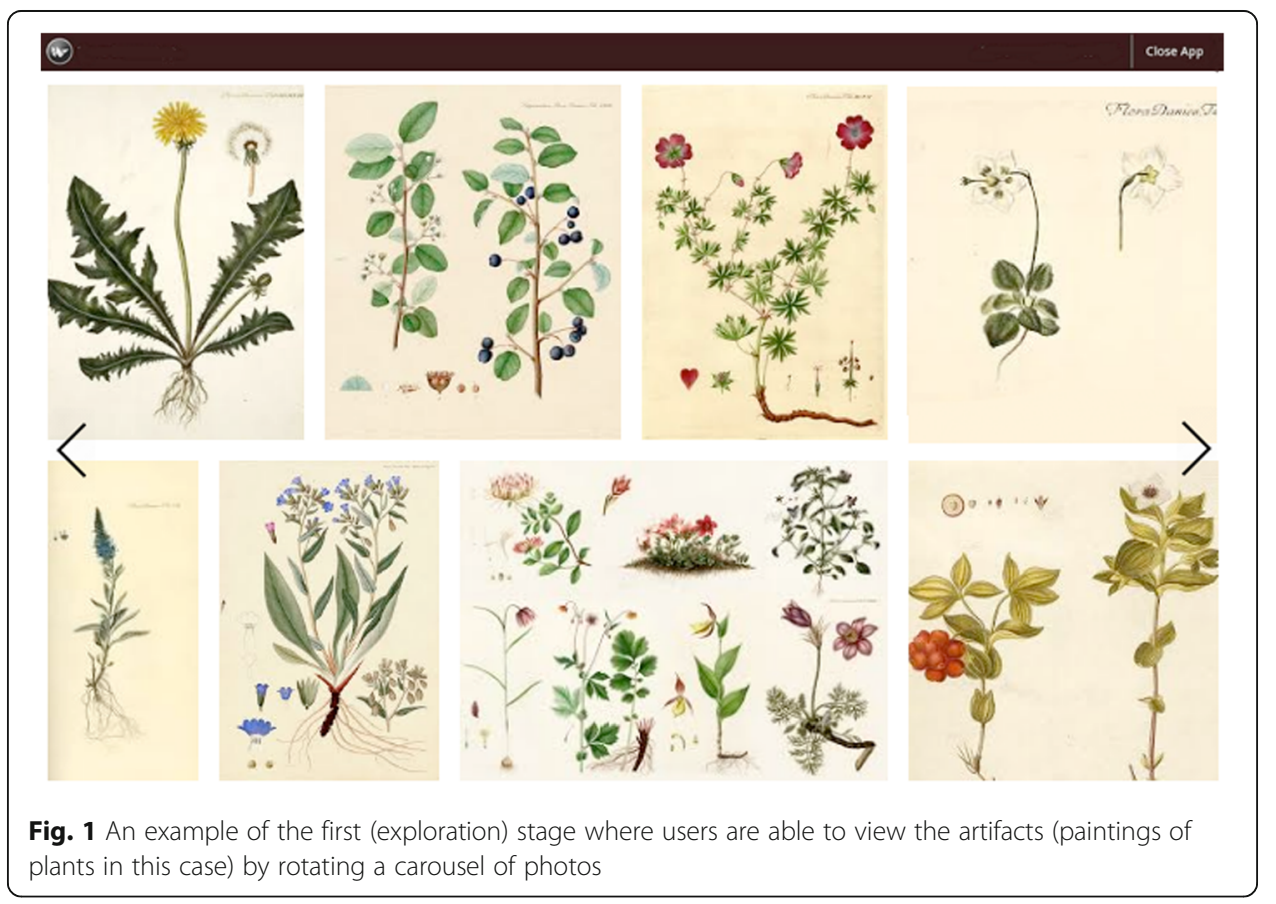




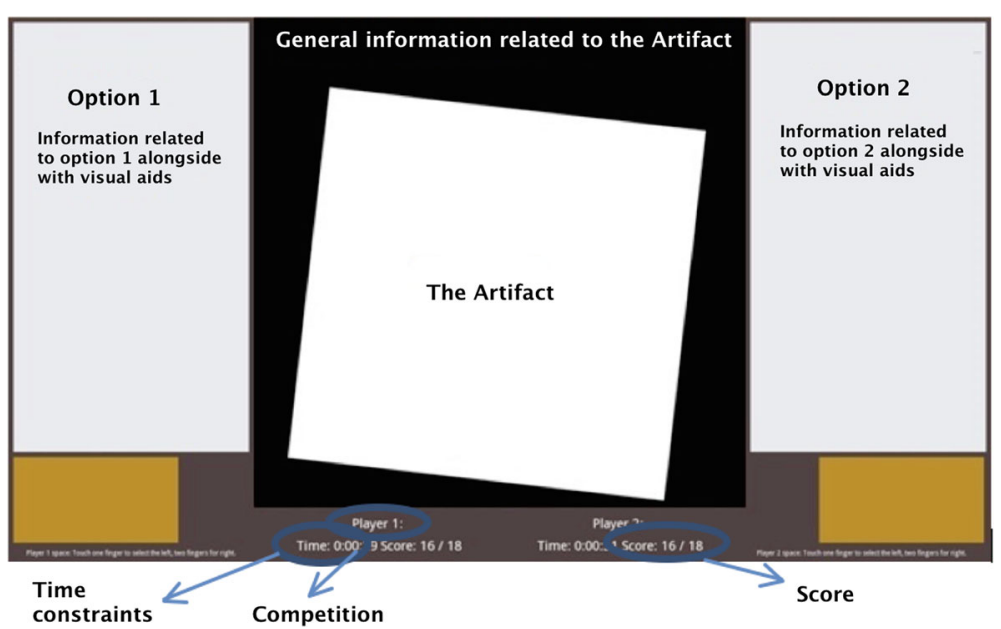

Fig. 2 The main elements of the application include the artifact in the center of the screen, the two alternative options in left and right side, the personal control areas in lower left and lower right part of the screen, the gamification elements in lower middle part of the screen

The third stage (called also creation stage) contains a drawing application where students use some basic connect-the-dots guidelines in order to create an artifact. Students can simultaneously interact on the surface in order to draw the represented by the dots artifact. This stage has been designed to encourage cooperation between students and allow them to express their creativity by reflecting their own view on the artifacts (Fig. 3). Instructors will have to design a collaborative creative task that, in order to be completed, will demand from the students to combine the things they have learned in the previous stages.

The proposed framework was developed in order to be easily adapted by the instructor for the desired extracurricular activity. Concerning the hardware, all that is needed is an interactive display. An off-the-shelf low-cost multi-touch monitor can be a stable and obvious option. Regarding the software, all three stages of the proposed framework are easily modifiable without the need of complex coding. In general, the model can be easily adjusted to the desired curriculum by loading and modifying the pictures of the artifacts and the corresponding texts.

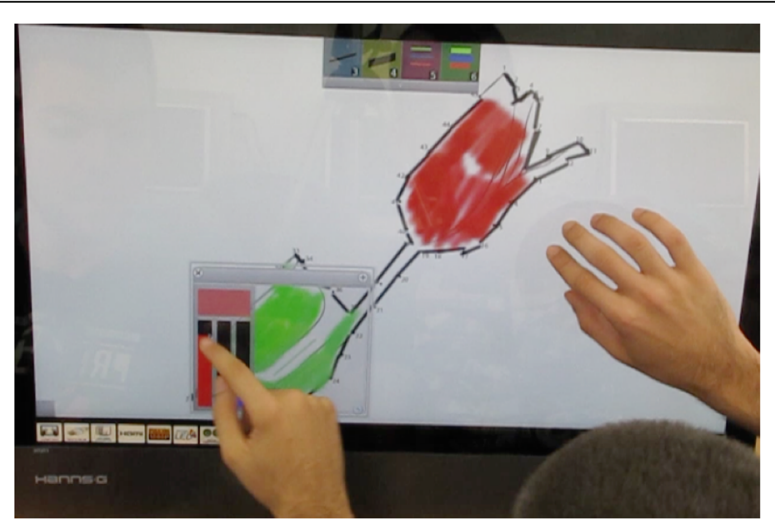

Fig. 3 A screenshot of the third stage (creation stage). Two students are working simultaneously in order to create an artifact 
This framework was designed so as to give more autonomy to users. Users are able to set their own goals and make their own choices (especially in the first exporatory stage and third creative stage). That is the main idea behind "meaningful gamification": helping the player to continue on their exploration of the desired context (Nicholson, 2015). Instead of considering gamification as a panacea for motivation, (Kim, 2015) propose that people's autonomy should be respected in any attempt to engage them and influence their behavior. Furthermore, a thorough understanding of the target audience, the nature of the target activity, and the gamified learning content is needed. Otherwise, gamification of education can become exploitative (Rughinis, 2013). By letting the users explore, search and understand the context with the help of the interactive screen (first stage of the framework), they preserve their intrinsic motivation. The proposed framework supports different affordances for play. It gives the opportunity to users to present a playful behavior, explore the content, and makes interacting with the activity more effortless and fun (especially in the third creative stage); Hence, instead of taking an action out of extrinsic motivation by using an external reward gamification scheme that might abstract users, we propose a framework that promotes learning, and hopefully allow the user to find and develop intrinsic motivations related to the activity (Knaving et al. 2013). In addition, with this framework, we deal with another drawback of gamification: over-competitiveness. During the second stage of the framework users are free to select whether they will play as a team or against each other while in the overall framework team-play and mutual understanding is supported.

In order to provide a proof of concept, we applied the proposed model to different exhibits. In particular, the interactive display application was developed in Kivy $\mathrm{MT}^{1}$ framework and was then adjusted to different archives. We have deployed the proposed framework in various settings such as a library museum and a deaf museum and we have also developed material for other scenarios (e.g. historical archives or ecology information). In Fig. 4 the application stage of the developed applications is depicted.

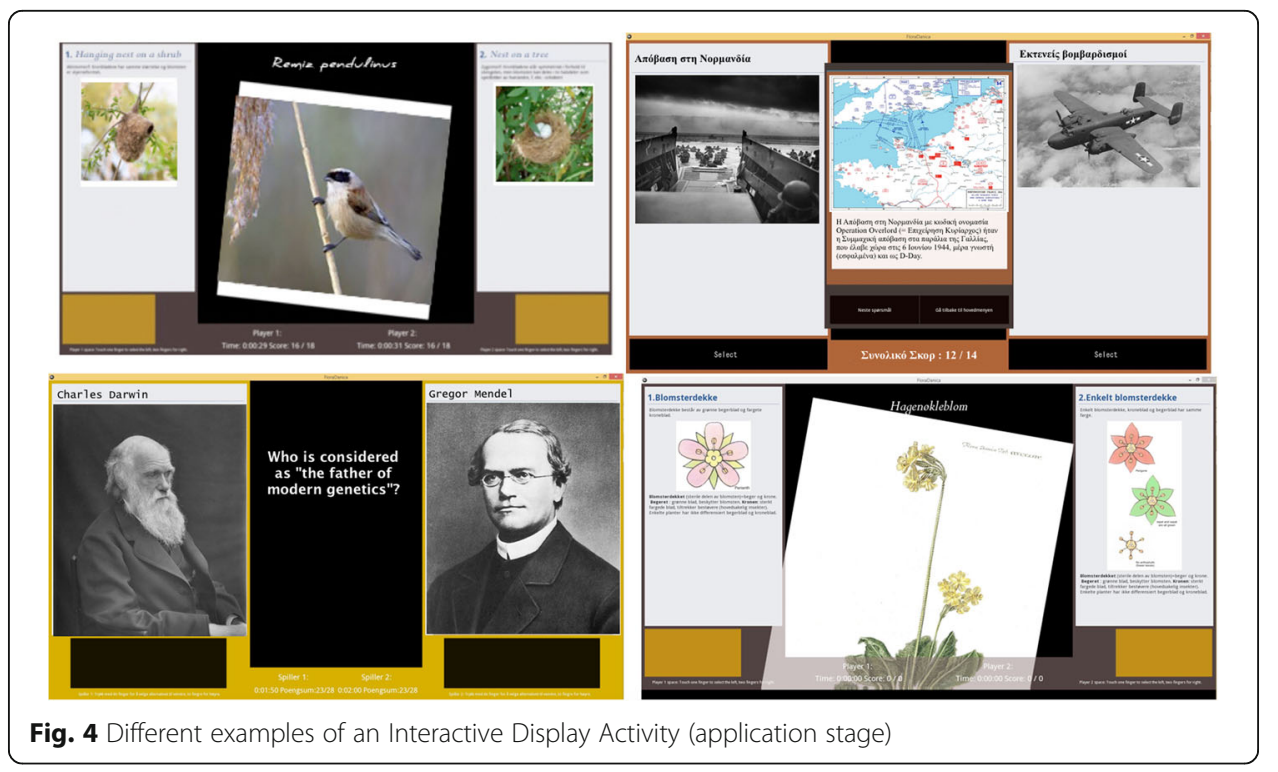




\section{Methodology of the study}

An initial empirical validation of the proposed framework took place within the context of an informal learning activity. The goal of this empirical validation is to provide the first data-based evidence regarding the effectiveness and acceptability of the proposed framework. The results should not be seen as a comparative evaluation of the proposed framework, but as an evaluation of the added value.

\section{Research design and procedures}

The research design of our study is a single-group time series design (Ross \& Morrison, 1996), involving repeated measurement of a group with the experimental treatment induced between two of the measures. The single-group time series design can be diagrammed as shown below (Table 2). As depicted, one group (Group 1) is observed $(\mathrm{O} 1)$ and receives the treatment $(\mathrm{X})$ and then observed again $(\mathrm{O} 2)$.

This study consists of pre (O1) and post (O2) measurements of knowledge acquisition and six attitudinal factors.

In particular, students visited the botanology museum in order to learn about the plants of their region. In the museum, a traditional guided tour took place during one and a half days. After the tour and students' interaction with the real artifacts, students visit the library and seek relevant information from various books and plant sketches. At the end of the typical museum visit and artifacts exploration, students received a knowledge acquisition assessment as well as an attitudinal questionnaire. Then students were divided into dyads and engaged with all three stages of the application for approximately $45 \mathrm{~min}$. In the beginning of their enrolment with the application, there was an orientation phase where students get acquainted with the interactive display and the multi-touch technology in general. We let the students work and understand how the system works for 5 to 10 min until they would have felt confident with the interactions. The content of GAID was the same with the typical visit (Flora Danica book). Flora Danica book is a plant archive, containing more than 3000 species of plants that can be found in Nordic countries. We chose a small number of plants and created a taxonomic key with the help of a domain expert. We refined the last details based on the pilot tests with the actual instructors/ teachers of the extracurricular activity. In the first (exploratory) stage of the proposed framework, the application allows the user to enlarge and rotate the main picture of the plants. Users are also able to see specific details of the plant (e.g. its sepals, blossoms). In the application stage students have to carefully identify which of the two options corresponds to the plant they have in front of them and make the appropriate selection. By making all the right selections in a number of steps they are lead to the family of the plant and some interesting information concerning the plant. In the creation stage, they are able to draw a portion of the plants that they found on the previous stages using a playful multi-finger chord interaction technique (Leftheriotis et al., 2016). After playing with the application, students were asked to complete a post knowledge acquisition assessment as well as an attitudinal questionnaire. This research is designed as shown in Fig. 5.

Table 2 The research design of the study

\begin{tabular}{llll}
\hline Group 1 & Time 1 Measure & Treatment & Time 2 Measure \\
& O1 & X & O2 \\
\hline
\end{tabular}




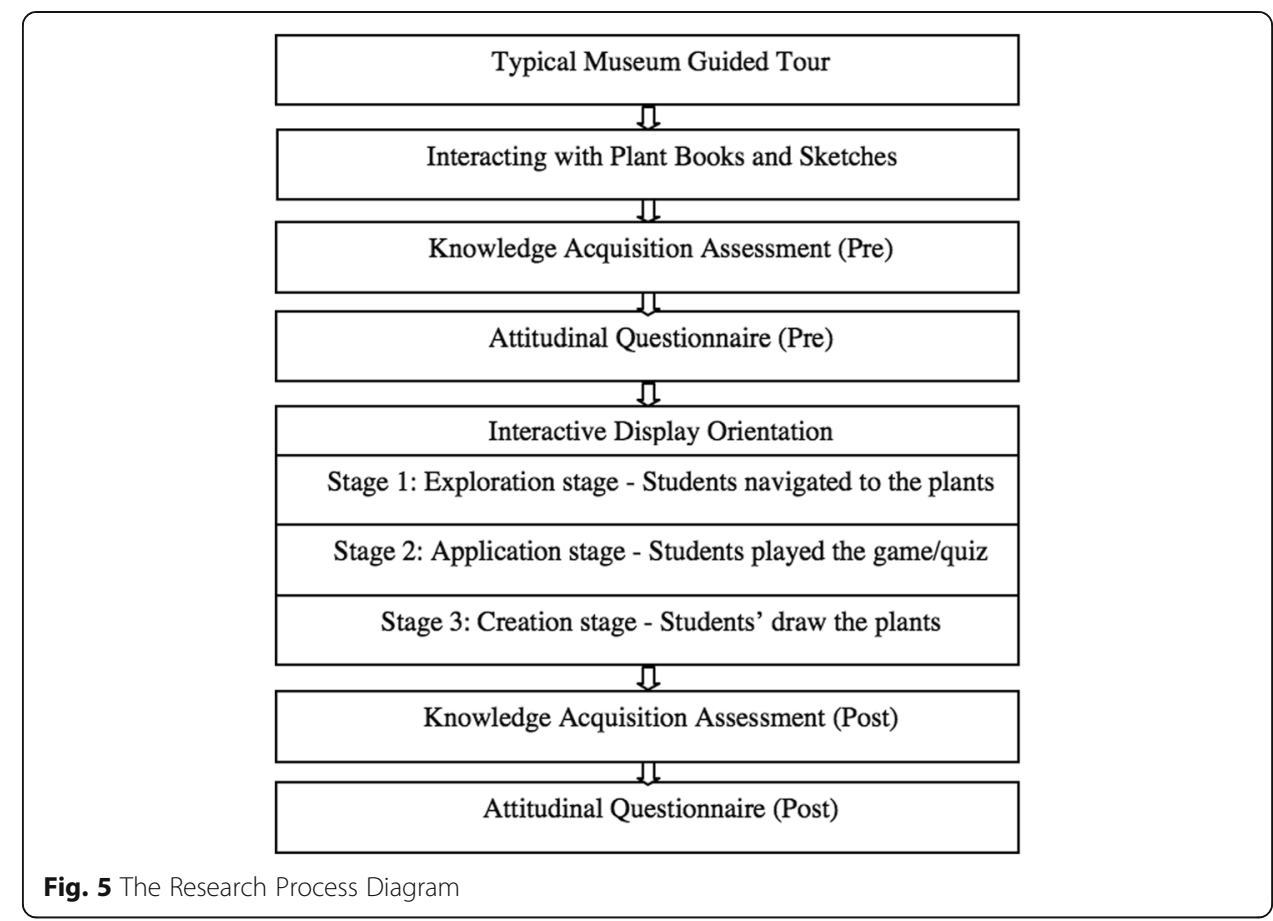

\section{Participants}

The sample of participants in this study consisted of 16 students. Of the 16 participants, 4 were boys and 12 girls. All of the students who participated in the experiment were 15-18 years old, enrolled in the third grade of high school, and were following the same syllabus. The experiment took place during an informal learning activity.

\section{Apparatus}

The experimental setup was based on a robust 27" inch all-in projective capacitive monitor with $5 \mathrm{~ms}$ response time, which was placed vertically. Students interacted with the multi-touch screen in dyads while being seated in front of the device. The screen was connected via USB to a Windows 7 environment installed on a Mac mini hardware; the system was able to identify 10 simultaneous touch points and this number of touches was adequate for the purpose of our application. There was a camera just behind them capturing their interactions.

\section{Measures}

A wide range of data was collected to address our research questions including cognitive tests, surveys, photos and observations. During all the experiments, at least one of the researchers was present to observe. The knowledge acquisition test was developed with the assistance of a domain expert, this test allowed us to capture the level of knowledge acquisition students obtained (we call it Learning Performance). The attitudinal survey was based on measures related to satisfaction, intention to participate, easiness, enjoyment, usefulness and control. In particular, Table 3 lists measure alongside with their operational definition. In all cases, 7-point Likert scales were used to measure the variables. 
Table 3 The factors used in the survey

\begin{tabular}{|c|c|c|c|}
\hline Factors & Operational Definition & $\begin{array}{l}\text { \# of items/ } \\
\text { questions }\end{array}$ & Source \\
\hline Satisfaction & $\begin{array}{l}\text { The degree to which a person positively } \\
\text { feels with the activity }\end{array}$ & 3 & Lin et al. (2005) \\
\hline Intention to Participate & $\begin{array}{l}\text { The degree of students' Intention to } \\
\text { participate in a similar activity }\end{array}$ & 4 & Shih (2008) \\
\hline Easiness & $\begin{array}{l}\text { The degree to which an individual } \\
\text { believes that attending the respective } \\
\text { activity is easy for him/her }\end{array}$ & 4 & Sanchez-Franco (2010) \\
\hline Enjoyment & $\begin{array}{l}\text { The degree to which the activity is } \\
\text { perceived to be personally enjoyable. }\end{array}$ & 3 & Venkatesh et al. (2002) \\
\hline Usefulness & $\begin{array}{l}\text { The degree to which an individual } \\
\text { believes that attending the respective } \\
\text { activity is useful for him/her. }\end{array}$ & 4 & Sanchez-Franco (2010) \\
\hline Control & $\begin{array}{l}\text { Refers to people's perceptions of } \\
\text { their ability to perform a given } \\
\text { behavior (e.g. participate and finish } \\
\text { a particular activity). }\end{array}$ & 2 & Shih (2008) \\
\hline
\end{tabular}

\section{Statistical analysis}

In order to identify any potential shift in students' learning performance and engagement during the activity, we used t-tests between the pre- and the post-results of the cognitive test and the survey. Hence, we were able not only to capture students' learning performance and engagement, but also to identify any gained value from their enrolment with the interactive display activity.

\section{Research findings}

Quantitative analyses on the data, obtained from the survey, was carried out. We first proceed to test the reliability of each measure using Cronbach $\alpha$ coefficient. As Table 4 shows, the result of the test revealed acceptable indices of reliability in all the factors $(>0.7)$. To investigate any possible relationships among the factors and explore factors that may be strongly related to each other, we used the Spearman's rank-correlation coefficient, statistically testing the null hypothesis which is equal to 0 . Spearman's test suggests that some of the factors are related, in some cases relatively strongly. More precisely, the most important positive relationships involve satisfaction and enjoyment and usefulness on the other side. In addition, enjoyment is positively related to easiness. These relations revealed the important role of satisfaction and enjoyment, which are related with most of students' attitudes. We present the results of Spearman's test in Table 4.

Table 4 Summary of measurement scales

\begin{tabular}{lllllll}
\hline Factors & CR & STF & ItP & EAS & ENJ & USE \\
\hline Satisfaction (STF) & 0.940 & 1.0 & & & & \\
Intention to Participate (ItP) & 0.928 & .156 & 1.0 & & & \\
Easiness (EAS) & 0.898 & $.775^{*}$ & .264 & 1.0 & & \\
Enjoyment (ENJ) & 0.934 & $.832^{*}$ & .152 & $.819^{*}$ & 1.0 & \\
Usefulness (USE) & 0.910 & $.814^{*}$ & .091 & $.738^{*}$ & $.777^{*}$ & 1.0 \\
Control (CON) & 0.937 & $.662^{*}$ & .187 & $.801^{*}$ & $.626^{*}$ & .766 \\
\hline
\end{tabular}

CR, Cronbach a; Correlation is significant at the ${ }^{*} 0.01$ level 
To examine the research question regarding the impact of the interactive display activity on students learning and engagement, we employed a $t$-test between the pre and post-test. As the outcome data in Table 5 illustrates, students' enrolment with the activity has indicated a significant effect on their learning.

We also employed a $t$-test with six dependent variables between the pre and postsurvey measures, in order to investigate whether there was an impact of the interactive display activity on students' engagement. According to the outcome data presented in Table 6, students' enrolment with the activity has indicated a significant effect on students' satisfaction, enjoyment and intention to participate. On the other hand, there was no impact on activity's easiness, usefulness and control (over the activity).

Table 6 shows that intention to participate has the lowest significance, and according to Fig. 6, it has the lowest increase among the variables that are significantly improved. In addition, satisfaction and enjoyment, which have higher significance, have a higher increase (more than 1 unit). Moreover, easiness, usefulness and control did not exhibit significant difference (Table 6); however, their impact on students' engagement seems positive (although not being significant). Overall, Fig. 6 clearly exhibits the generally positive (and in some cases significant) influence of the interactive display activity on students' engagement.

\section{Discussion}

The study reported in this paper was focused on two main issues: 1) investigating a model for developing gamified activities on interactive displays and 2) evaluating the effect of gamified interactive display technology as a means of consolidating knowledge and improving engagement.

\section{A model for developing gamified activities on interactive displays}

Most of the studies found in the literature are focused on the positive effects of an interactive display (such as a multi-touch screen) on users' experience (Leftheriotis \& Chorianopoulos, 2011), performance (Watson et al., 2013), engagement (Hornecker, 2008), or collaboration aspects (Higgins et al., 2012). There are many exploratory studies with multi-touch surfaces especially on a museum context (e.g. Horn et al., 2012, Hornecker, 2008). Studies like those mentioned give us insights and design principles concerning the development and design of interactive applications/games in an education context (e.g. Antle et al., 2011). However, apart from the general design guidelines or software/hardware frameworks that can be found in the literature (e.g. Ciocca et al., 2012; Dillenbourg \& Evans, 2011) there is a lack of frameworks that would facilitate the educational purposes with the use of gamified activities on a multitouch surface. Researchers, either have to develop new types of interactive applications (as in Horn et al., 2012) or make use of existing tasks (as in Rick \& Rogers, 2008) embedding gamification aspects.

Table 5 Testing the effect of interactive displays activity of students learning performance

\begin{tabular}{llll}
\hline & Mean (S.D.) & & $t$ \\
Learning Performance & Pre & Post & $3.48^{*}$ \\
\hline
\end{tabular}

${ }^{*}$ Correlation is significant at the 0.05 level 
Table 6 Testing the effect of interactive displays activity of students' engagement

\begin{tabular}{|c|c|c|c|c|}
\hline & \multicolumn{2}{|l|}{ Mean (S.D.) } & \multirow[t]{2}{*}{$t$} & \multirow[t]{2}{*}{$p$} \\
\hline & Pre & Post & & \\
\hline Satisfaction & $4.69(0.99)$ & $5.82(1.14)$ & $2.99^{\mathrm{a}}$ & 0.005 \\
\hline Intention to participate & $3.35(0.82)$ & $4.23(1.12)$ & $2.54^{\mathrm{a}}$ & 0.017 \\
\hline Easiness & $4.73(1.13)$ & $5.48(1.24)$ & 1.79 & 0.084 \\
\hline Enjoyment & $4.32(1.14)$ & $5.97(0.96)$ & $4.43^{\mathrm{a}}$ & 0.000 \\
\hline Usefulness & $4.72(1.10)$ & $5.28(1.15)$ & 1.41 & 0.170 \\
\hline Control & $4.96(1.65)$ & $5.45(1.60)$ & 0.85 & 0.401 \\
\hline
\end{tabular}

${ }^{\mathrm{a} C o r r e l a t i o n}$ is significant at the 0.05 level

By introducing a customizable framework to develop gamified interactive display applications and support informal learning activities in exhibition-like environments, we focus on the value of the multi-touch technology and multi-user affordances as important means to support students' interaction with the artifacts, experience and learning. Multi-touch displays are very promising in facilitating collaborative learning activities, as also indicated in the literature (Piper \& Hollan, 2009). This is supported by the fact that, collaboration among students was the most important aspect observed during the field study. Students worked together, helping each other when they got into difficulties, suggesting solutions to problems emerging during the play, and exchanging information.

\section{Adapting the framework to the context or the aims of the study}

Researchers are able to adapt our framework into the context they are interested in, being focused more on the topics they want to investigate while practitioners have a tool that according to our empirical study works in favor of students' satisfaction, enjoyment and intention to participate to similar activities.

The instructors/experimenters are able to formulate the proposed frameworks' three stages and thus adapt it to the context of the extracurricular activity in which they are

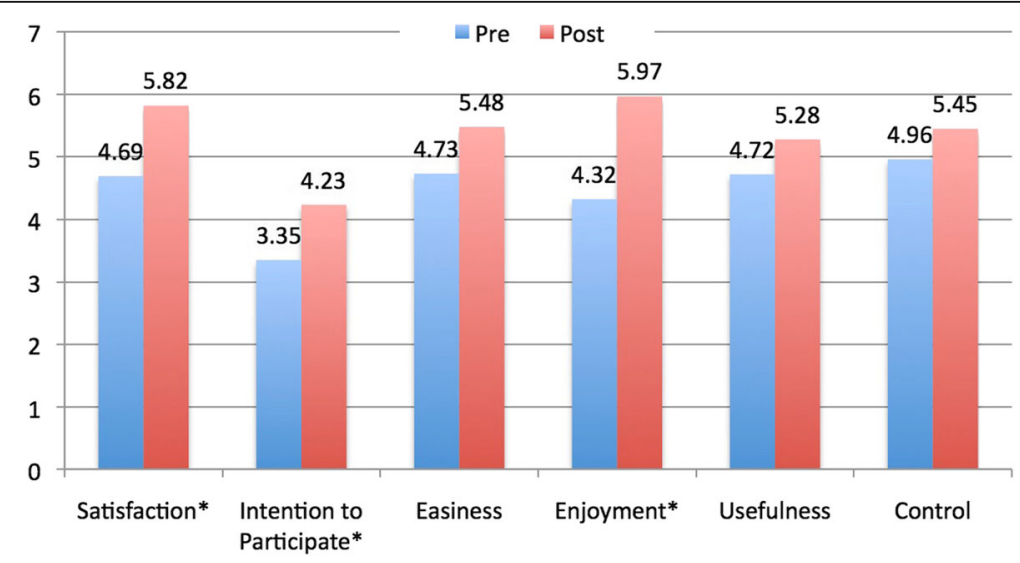

Fig. 6 The influence of the interactive display on students' engagement ${ }^{*}$ depicts significant difference) 
interested. For instance, during the exploration stage of this study, we presented to the students a carousel type of menu where the artifacts of the museum were depicted as different options. Students were able to rotate the carousel menu using the common swipe gesture and touch whatever artifact attracted their attention. In the event of a touch, a new screen with larger visual material of the artifact along with detailed information would appear. Students then were able to play by rotating/moving and enlarging the artifact so as to find out its details or its unique characteristics described in the text (Fig. 7). An opportunity to download visual material related to the selected artifact from the Internet was also apparent and children found this option intriguing according to their recorded interactions. This option allowed the students to understand how the artifact they were interacting with, is well connected to the real world. Both in the exploration and application stage, students were able to move, rotate and enlarge the respective material. As in Higgins et al. (2012), this affordance facilitated the joint attention and seems likely to have facilitated the quicker development of a shared understanding of the task.

During the application stage of the proposed framework, we let the students play first on the team mode and then on the versus mode. We wanted to see whether there would be different interaction strategies between these two modes. The way the students interact between each other on these two gameplay modes was indeed different. Based on our observations and video log files, during the versus mode, the gamification elements such as their total score and time had an underlying effect on the way they were working with the application. They were simply trying to "win" their opponent. This effect prolonged the time they needed in order to complete the quiz task: a) students were thinking twice about the options they had on the game so as to maximize

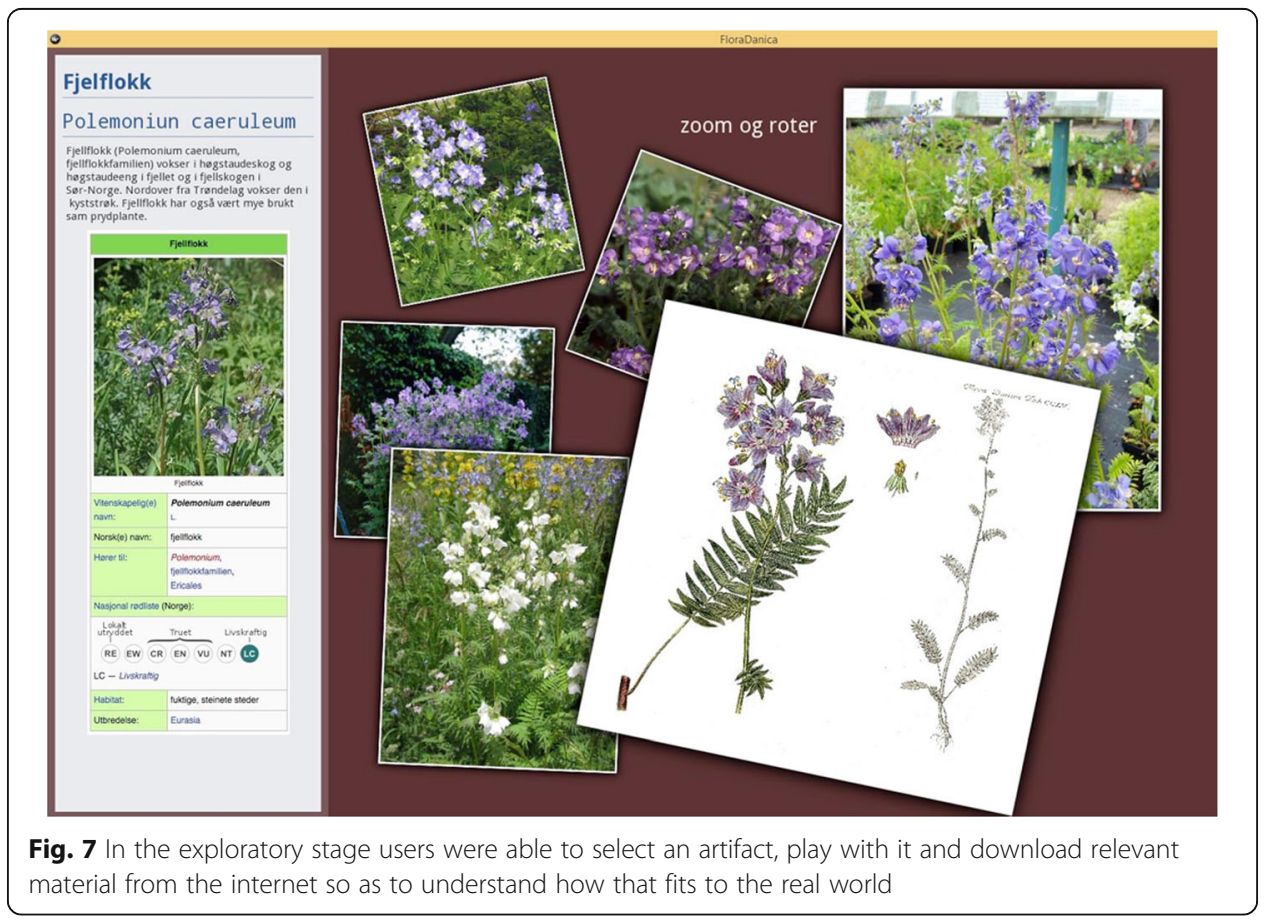


their score, b) students were reluctant to answer and they were waiting for their opponent's first move when they did not know the answer. In the team-mode, where the dyads were working together as a team, students were more communicative about the alternatives they had. However, users had lost partially their interest to respond fast and the "gaming" mood they had in the versus mode even though they could see their own total score and total time on the screen. In another study, Nicholson (2012) describes "meaningful gamification" as the one that focuses on introducing elements of play instead of elements of scoring. Based on a simple behaviour model by Fogg (2009) that is often used in game context (Hägglund, 2012), there are three required factors underlying the human behaviour: motivation, ability and trigger. Bearing in mind that the task was a simple quiz-task relevant to the original exhibition tour they had before, users should have been motivated and triggered. The competitive situation in versus mode motivated users to engage with the task while score points along with time not only triggered them to carry it out, but made users to feel good about doing it (Hägglund, 2012). According to what the students replied in the questionnaires, their intention to participate to similar activities in the future was high.

In the creation stage of the model, the aim is to let the students be expressive and creative. In this stage, we employed the well-known connect the dots game and adapted it making it a multi-touch game. In this study, we let the users draw artifacts that they were able to see during the original exhibition tour. Students were free to choose colours and paint/draw the artifacts according to their preference with different tools and different styles. Once again, this was a collaborative procedure and students had to cooperate, negotiate, use the affordances of the multi-touch device and finally construct "their own unique artifact" that would finally compare with other teams' artifacts. In the case of an interactive surface, it is mostly the low-level implementation - the direct touch interaction technique - that augments user experience and thus making the users express their own creativity even if they do not have a large number of tools (Giannakos \& Leftheriotis, 2015).

\section{Evaluating the results of the field study}

Regarding the effect of gamified interactive display technology as a means of consolidating knowledge and improving engagement, the field study demonstrated that students enjoyed the game and were actively engaged; they liked playing in groups or competing with each other. Students gave significantly more correct answers to the cognitive test performed after the interactive display game-play. Incorporating gamified interactive display applications in an informal learning activity are found to be very effective on supporting the learning process. The results show that students learn and react favorably towards the interactive surfaces in accordance to previous studies (e.g. Jackson et al., 2013). It seems that students feel more engaged and in flow while playing with the interactive surface, and thus the hedonic metrics are significantly improved as in previous studies (Leftheriotis et al., 2011). Despite the fact that the pragmatic metrics, such as control, usefulness and easiness are not significantly improved, all metrics show an increase even though most of the students did not have previous experience with this type of interaction. We believe that it might be easier and more natural for students to feel in control while working with the actual artifact instead of a visual replica, and since students had an 
actual visit with a botanologist in the field before the experiment, this might have influenced their decisions regarding pragmatic metrics. However, the enjoyment and flow they have been feeling while working with the gamified task, have significantly improved their intention to participate in similar activities in the future.

Based on the video recordings, children seem to enjoy interaction with the application while in the team mode. The gamification elements played an important role so as to make the application engaging. "What are the others' score?" was a common question that was recorded in at least half of the teams participated. In fact, the players although playing as a team, they were still feeling competitive against the other teams score. In addition to score, time affected the game since users were trying to be as fast as possible without mistakenly answer a question. The sound of the right answer was a relief for them and they seemed to enjoy it. As it was expected, different teams employed different strategies. In general, students have been mutually discussing about their answer, however there was a small portion of teams in which there was a bold user that played a more important role, influencing their decision.

On the other hand, when students played on the versus mode, they were competing between each other feeling engaged with the application. In Fig. 8, some moments of intense playful interaction are shown. One user is protecting her personal territory on the screen so as to prevent the other user from revealing her answer.

\section{Limitations}

Despite the fact that, the influence of our implementation of the described model had a positive effect on users' engagement (as the Fig. 6 also depicts), we want to emphasize that our findings are clearly preliminary with inevitable limitations. Due to the limitations of the extracurricular activity there was a relatively small sample size, the total number of the students was 16. In addition, most of the students were girls. With a small sample size there is less statistical power. Howerver, in most metrics the differences we found in pre and post surveys are significantly important. In addition, the presented results are in accordance with what we saw during the experiment, with the video recordings and the discussions we had with the students after the experimental task. In this study, we wanted to present databased evidence regarding the effectiveness and acceptability of the proposed framework. Although the results of this study clearly present these trends, we encourage researchers to

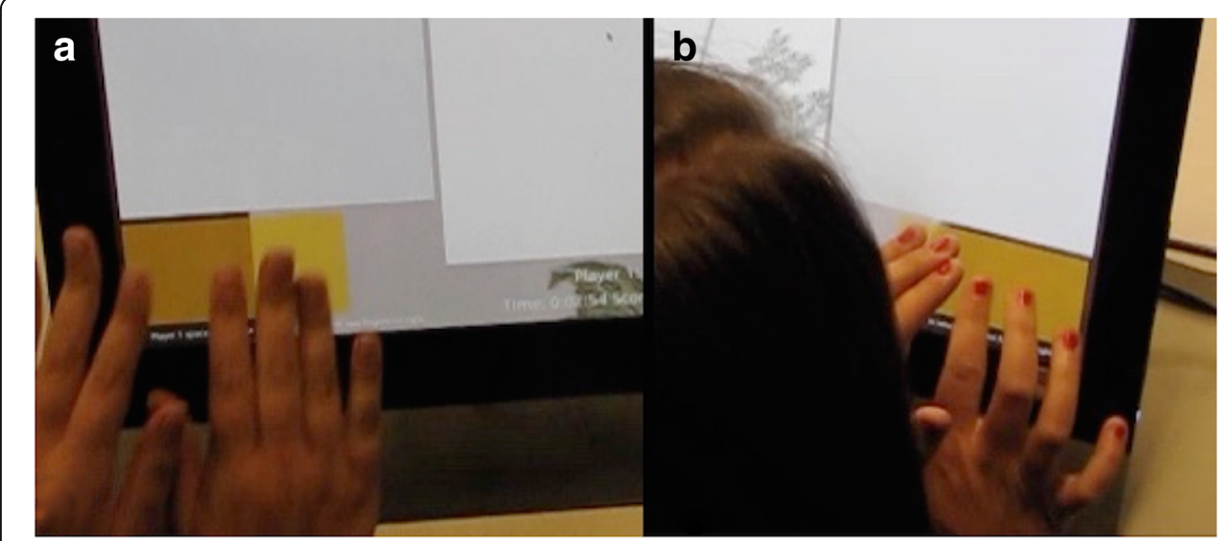

Fig. 8 In both situations users are enjoying interaction and laugh during play: a User on the left is trying to confuse the other user about her selection, $\mathbf{b}$ User on the right is trying to conceal her selection 
conduct further experiments with larger sample size and diverse applications so as to evaluate the proposed framework and present statistically solid results.

One other limitation is that, althought there are only two items in the Control factor, which makes it weak for statistical analysis, we decided to keep these results in this study. As for the internal validity of the empirical study, data are based on a self-reported method, log-files and assessments. Other in-depth methods such as semi-structured interviews could provide a complementary picture of the findings through data triangulation. As for external validity, the subjects were high school students, which may somewhat limit the generalizability of our results. Nevertheless, the insights drawn are not connected with the subjects' background and can be generalized to other students.

\section{Conclusion}

Although a relatively new term, gamification practices are more and more embedded in many domains such as education, information studies, social media and application design or even health. However, as Seaborn et al. (2015) point out "little empirical work has sought to validate gamification as a meaningful concept and provide evidence of its effectiveness as a tool for motivating and engaging users in non-gaming contexts". In addition, Hamari et al., (2014) claim that "gamification does work but..." the effects of gamification are greatly dependent on the context. In this study we showed that gamified applications in multi-touch displays are able to promote students' learning and engagement, especially when these applications are integrated within an informal learning activity, such as a school trip, as well as traditional school lessons.

We presented an adaptable model that works as a general schema that might be instantiated specifically for different cases in a teaching environment for developing gamified activities for multi-touch devices and the results of a field study where students have been engaged with an interactive display application during an extracurricular activity. Based on this study, the developed framework that employs gamified characteristics on the three stages (exploration, application, creation) of the interactive display application produced improved results concerning students' engagement metrics. By incorporating GAID to a traditional informal learning activity, we found that students' knowledge acquisition, satisfaction, enjoyment and intention to participate on similar events in the future are significantly improved.

The early results of this study should not be seen as a rigorous evaluation of the proposed model, but as early insights and reflections rising from a particular case study as well as empirical evidence for the further development of the framework. Future work should be done to validate our proposed model in other contexts as well.

\section{Endnote}

${ }^{1}$ Kivy - open source python library for rapid development of applications that make use of innovative user interfaces, such as multi-touch apps. URL: http://kivy.org

Acknowledgements

We would like to thank the participants of this study. We would also like to thank archaeologist Aleka Angeletaki and biologist Gavriella Papastefanou for their assistance in the experimental task. 
Competing interests

The authors declare that they have no competing interests.

\section{Publisher's Note}

Springer Nature remains neutral with regard to jurisdictional claims in published maps and institutional affiliations.

Received: 26 September 2016 Accepted: 11 May 2017

Published online: 30 May 2017

\section{References}

A.N. Antle, A. Bevans, J. Tanenbaum, K. Seaborn, S. Wang. Futura: design for collabo-rative learning and game play on a multi-touch digital tabletop. In Proceedings of the fifth international conference on Tangible, embedded, and embodied interaction, (ACM Press, 2011), 93-100

C. Ardito, R. Lanzilotti, M.F. Costabile, G. Desolda, Integrating traditional learning and games on large displays: an experimental study. J. Educ. Technol. Soc. 16(1), 44-56 (2013)

B.J. Fogg. A behavior model for persuasive design. In Proceedings of the 4th international Conference on Persuasive Technology, (ACM, 2009), p. 40

S. Buisine, G. Besacier, A. Aoussat, F. Vernier, How do interactive tabletop systems influence collaboration? Comput. Hum. Behav. 28(1), 49-59 (2012)

J. Cassell, K. Ryokai, Making space for voice: technologies to support children's fantasy and storytelling. Pers. Ubiquit. Comput. 5(3), 169-190 (2001)

G. Ciocca, P. Olivo, R. Schettini, Browsing museum image collections on a multi-touch table. Inf. Syst. 37(2), 169-182 (2012)

S. Deterding, D. Dixon, R. Khaled, \& L. Nacke. From game design elements to gameful-ness: defining gamification. In Proceedings of the 15th International Academic MindTrek Conference: Envisioning Future Media Environments, (ACM Press, 2011), 9-15

C. Dichev, D. Dicheva, G. Angelova, G. Agre, From gamification to gameful design and gameful experience in learning. Cybern. Inf. Technol. 14(4), 80-100 (2014)

P. Dillenbourg, M. Evans, Interactive tabletops in education. Comp. Supported Collaborative Learn. 6, 491-514 (2011)

A. Domínguez, J. Saenz-de Navarrete, L. De-Marcos, L. Fernández-Sanz, C. Pagés, J.-J. Martínez-Herráiz, Gamifying learning experiences: practical implications and outcomes. Comput. Educ. 63(1), 380-392 (2013)

E. Hornecker. "I don't understand it either, but it is cool"-visitor interactions with a multi-touch table in a museum. In Proceedings of Horizontal Interactive Human Computer Systems, IEEE TABLETOP, (2008), 113-120

P.A. Ertmer, T.J. Newby, Behaviorism, cognitivism, constructivism: comparing critical features from an instructional design perspective. Perform. Improv. Q. 26(2), 43-71 (2013)

M. Giannakos, \& I. Leftheriotis. How Space and Tool Availability Affect User Experience and Creativity in Interactive Surfaces? In Proceedings of the 2015 ACM SIGCHI Conference on Creativity and Cognition, (ACM, 2015), pp. 201-204

S. Haesler, K. Obernesser, T. Raupp, C. Jahnke, J. Stapf, J. Bräker, ... \& F. Steinicke. Edutainment \& Engagement at Exhibitions: A Case Study of Gamification in the Historic Hammaburg Model. Mensch und Computer 2016Tagungsband (2016).

J. Hamari, J. Koivisto, H. Sarsa, Does gamification work?-a literature review of empirical studies on gamification, in Proceedings of System Sciences (HICSS), 2014 47th Hawaii International Conference, IEEE, 2014, pp. 3025-3034

S. Higgins, E. Mercier, L. Burd, A. Joyce-Gibbons, Multi-touch tables and collaborative learning. Br. J. Educ. Technol. 43(6), 1041-1054 (2012)

U. Hinrichs, S. Carpendale. Gestures in the wild: studying multi-touch gesture sequences on interactive tabletop exhibits. In Proceedings of the SIGCHI Conference on Human Factors in Computing Systems (CHI'11), (ACM Press, 2011), 3023-3032

M. Horn, Z. Leong, F. Block, J. Diamond, E.M. Evans, B. Phillips, C. Shen. BATs and APEs: Designing an interactive tabletop game for natural history museums. In Proceedings of the SIGCHI Conference on Human Factors in Computing Systems (CHI'12), (ACM Press, 2012), 2059-2068

W.Y. Hwang, R. Shadiev, C.W. Tseng, Y.M. Huang, Exploring effects of multi-touch tabletop on collaborative fraction learning and the relationship of learning behavior and interaction with learning achievement. J. Educ. Technol. Soc. 18(4), 459-473 (2015)

A.T. Jackson, B.J. Brummel, C.L. Pollet, D.D. Greer, An evaluation of interactive tabletops in elementary mathematics education. Educ. Technol. Res. Dev. 61(2), 311-332 (2013)

B. Kim, Designing gamification in the right way. Libr. Technol. Rep. 51(2), 29-35 (2015)

J.T. Kim, W.H. Lee, Dynamical model for gamification of learning (DMGL). Multimedia Tools Appl. 74(19), 8483-8493 (2015)

E. Klopfer et al., Mystery at the museum: a collaborative game for museum education, in In Proceedings of 2005 International Conference on Computer-Supported Collaborative Learning (CSCL'05), ACM Press, 2005, pp. 316-320

K. Knaving, \& S. Björk. Designing for fun and play: exploring possibilities in design for gamification. In Proceedings of the First International Conference on Gameful Design, Research, and Applications, (ACM, 2013), pp. 131-134

I. Leftheriotis, \& K. Chorianopoulos. User experience quality in multi-touch tasks. In Proceedings of the 3rd ACM SIGCHI symposium on Engineering interactive computing systems (EICS'11), (ACM Press, 2011), 277-282

I. Leftheriotis, M.N. Giannakos, K. Chorianopoulos, L. Jaccheri. Interaction Space of Chords on a Vertical Multi-touch Screen. In Proceedings of the 2015 International Conference on Interactive Tabletops \& Surfaces (ITS'14), (ACM Press, 2015), 355-360

I. Leftheriotis, K. Chorianopoulos, L. Jaccheri, Design and implement chords and personal windows for multi-user collaboration on a large multi-touch vertical display. Hum. Centric Comput. Inf. Sci. 6(1), 14 (2016)

C.S. Lin, S. Wu, R.J. Tsai, Integrating perceived playfulness into expectation-confirmation model for web portal context. Inf. Manag. 42(5), 683-693 (2005) 
C. Linehan, B. Kirman, S. Lawson, G.G. Chan. Practical, appropriate, empirically-validated guidelines for designing educational games. In Proceedings of the SIGCHI Conference on Human Factors in Computing Systems, (CHI'11), (ACM Press, 2011), 1979-1988

M.N. Giannakos, D. Jones, H. Crompton, N. Chrisochoides. Designing Playful Games and Applications to Support Science Centers Learning Activities. In Universal Access in Human-Computer Interaction. Universal Access to Information and Knowledge, (Springer LNCS, 2014), vol 8514, 561-570

P. Mildner, N. Stamer, \& W. Effelsberg. From Game Characteristics to Effective Learning Games. In Joint International Conference on Serious Games. (Springer International Publishing, 2015), pp. 51-62

P. Hägglund. Taking gamification to the next level. Umeå University, Department of Computing Science, PhD Thesis, (2012)

A.M. Piper \& J.D. Hollan. Tabletop Displays for Small Group Study: Affordances of Paper and Digital Materials. In Proceedings of the SIGCHI Conference on Human Factors in Computing Systems, (CHI'09), (ACM Press, 2009), 1227-1236

R. Rughinis. Gamification for productive interaction: Reading and working with the gamification debate in education. In Information Systems and Technologies (CISTI), 2013 8th Iberian Conference on, (IEEE, 2013), pp. 1-5

J. Rick, \& Y. Rogers. From DigiQuilt to DigiTile. Adapting educational technology to a multi-touch table. In Proceedings of Horizontal Interactive Human Computer Systems, IEEE TABLETOP, (2008), 73-80

S.M. Ross, G.R. Morrison. Experimental research methods. Handbook of research for educational communications and technology: A project of the association for educational communications and technology, (1996), 1148-1170

S. Nicholson. A recipe for meaningful gamification. In Gamification in education and business. (Springer International Publishing, 2015), pp. 1-20

S. Nicholson. A user-centered theoretical framework for meaningful gamification. In proceedings of Games + Learning + Society 8.0, (2012), pp. 223-229.

M.J. Sanchez-Franco, WebCT-The quasimoderating effect of perceived affective quality on an extending Technology Acceptance Model. Comput. Educ. 54(1), 37-46 (2010)

K. Seaborn, D.I. Fels, Gamification in theory and action: a survey. Int. J. Hum. Comput. Stud. 74, 14-31 (2015)

H.P. Shih, Using a cognition-motivation-control view to assess the adoption intention for Web-based learning. Comput. Educ. 50(1), 327-337 (2008)

R.J.W. Sluis, I. Weevers, C.H.G.J.V. Schijndel, L. Kolos-Mazuryk, S. Fitrianie, \& J.B.O.S. Mar-tens. Read-lt: Fiveto-seven-year-old Children Learn to Read in a Tabletop Environment, In Proceedings of 2004 International Conference on Interaction Design with Children (IDC'04), (ACM Press, 2004), 73-80

R.W. Songer, \& K. Miyata. A playful affordances model for gameful learning. In Proceedings of the Second International Conference on Technological Ecosystems for Enhancing Multiculturality, (ACM, 2014), pp. 205-213

E. Tse, J. Schöning, J. Huber, L. Marentette, R. Beckwith, Y. Rogers, \& M. Mühlhäuser. Child Computer Interaction: Workshop on UI Technologies and Educational Pedagogy. In Proceedings of the SIGCHI Conference on Human Factors in Computing Systems, (CHI 11), (ACM Press, 2011), 2445-2448

V. Venkatesh, C. Speier, M.G. Morris, User acceptance enablers in individual decision making about technology: Toward an integrated model. Decis. Sci. 33(2), 297-316 (2002)

D. Watson, M. Hancock, R. Mandryk. and M. Birk. Deconstructing the touch experience. In Proceedings of the 2013 International Conference on Interactive Tabletops \& Surfaces (ITS'13), (ACM Press, 2013), 199-208.

C.L. Weitze, \& R. Ørngreen. Concept Model for designing engaging and motivating games for learning. In Meaningful Play 2012 Conference Proceedings, (2012)

P. Zaharias, D. Michael, Y. Chrysanthou, Learning through multi-touch interfaces in museum exhibits: An empirical investigation. J. Educ. Technol. Soc. 16(3), 374-384 (2013)

\section{Submit your manuscript to a SpringerOpen ${ }^{\circ}$ journal and benefit from:}

- Convenient online submission

- Rigorous peer review

- Open access: articles freely available online

- High visibility within the field

- Retaining the copyright to your article 